Revista Iberoamericana, Vol. LXXIX, Núm. 242, Enero-Marzo 2013, 75-94

\title{
LA REVOLUCIÓN COMO NOVELA - ¿LA NOVELA DE LA REVOLUCIÓN? SOBRE LA METAFORIZACIÓN DE LA REVOLUCIÓN SANDINISTA EN LA NARRATIVA NICARAGÜENSE
}

\author{
POR \\ WERnER MACKENBACH \\ Universität Potsdam
}

Treinta años después del triunfo de la Revolución Sandinista la memoria de ese proceso sigue siendo un campo conflictivo, especialmente en una situación en la que este trigésimo aniversario coincide con el ejercicio de poder por un gobierno que reclama la continuidad política y personal del "sandinismo revolucionario". Entre la monumentalización del 19 de julio y los “héroes y mártires”, la instrumentalización de los recuerdos del movimiento revolucionario en beneficio del actual gobierno "resandinista" y las voces de (ex-)militantes políticos que vivieron en carne propia las décadas de la guerra, insurrección y revolución, se ha librado una verdadera batalla de la memoria ${ }^{1}$ por la supremacía interpretativa.

Es obvio que el derecho a la memoria y su articulación, publicación y divulgación se han vuelto un requisito fundamental, una conditio sine qua non para que las sociedades centroamericanas que más han sufrido los traumas de los conflictos armados, las masacres y los genocidios - pero también Centroamérica como región en conjunto que en los últimos treinta años y más ha sido afectada por los conflictos armados y sus repercusiones- superen las secuelas de esas décadas y se abran a los caminos hacia un futuro más justo y democrático.

En el campo literario han sido particularmente las narrativas testimoniales, de memoria y autobiográficas, las que han servido como punta de lanza en la polémica por la memoria "verdadera” y legítima. En el caso nicaragüense, destacan en el período de "posguerra" y "pos-sandinista", es decir, a partir de los años noventa las memorias publicadas por Violeta Barrios de Chamorro, Ernesto Cardenal, Sergio Ramírez, Gioconda Belli, Fernando Cardenal y Humberto Ortega -todos ellos militantes o líderes políticos

1 En su estudio sobre las experiencias de las comisiones de verdad en América Latina el psicólogo costarricense Ignacio Dobles Oropeza afirma que "la metáfora más adecuada para tratar las tareas de la memoria no es la de una 'mesa de discusión' ni de las 'negociaciones', sino la de las 'batallas de la memoria’” (306-7). 
de la "década sandinista"-. En contraposición, la novelística (y la cuentística) -como literatura en sentido estrecho de la palabra, es decir de ficción- parece no haberse ocupado de la problemática. Por lo menos así lo ha sugerido la crítica literaria: ya en 1991 el crítico puertorriqueño Ramón Luis Acevedo reclamó casi en un tono lleno de reproches que en Nicaragua todavía no se había escrito la novela sobre la Revolución Sandinista "que todos esperamos" (163); y en 1998 el crítico nicaragüense Napoleón Chow constató en un artículo publicado en el periódico La Prensa con el título "Esperando a la gran novela sandinista" que existía una serie de estudios sociológicos sobre el tema, "pero la revolución vista con ojos subjetivos, con ojos nicaragüenses de escritor creativo, preferiblemente de alguien que se entregó o sigue entregado a ella: eso está por verse" (11A).

Todavía a inicios de los años noventa Acevedo señaló como explicación principal de la supuesta no existencia de novelas sobre la Revolución Sandinista la predominancia de la poesía (lírica) y del testimonio (ver 163). Para Chow, hasta a finales de esa década una especie de dominancia discursiva sandinista y autocensura imposibilitaron la emergencia de novelas sobre los acontecimientos recientes y con figuras literarias con claras referencias a personas de la historial real. Publicar textos de este tipo resultaría siempre muy peligroso porque casi todos los comandantes y líderes del pasado sandinista estaban vivos y tenían mucho poder. Por esa razón-según su resumen hecho un poco antes de terminar el siglo- todavía se tenía que esperar la novela de la Revolución Sandinista, "de su inicio empecinado y aún heroico, de su victoria extática, de su gobierno sin rumbo cierto, y, como casi todos los experimentos sociales, de su inevitable ocaso” (4).

\section{LA NOVELA DE LA REVOLUCIÓN-LA REVOLUCIÓN EN LA NOVELA}

Tal vez uno puede aceptar el juicio de que no existe "la gran novela sandinista". Sin embargo, por un lado, es de cuestionar si esta novela de la Revolución Nicaragüense algún día será escrita y canonizada como ha sucedido en el caso de la novela de la Revolución Mexicana, faltando a los acontecimientos en Nicaragua el ímpetu y la relevancia histórica y cultural de la Revolución Mexicana. No por casualidad, y como ya mencioné, los poetas y narradores más importantes de Nicaragua-Ernesto Cardenal, Sergio Ramírez y Gioconda Belli- han tratado la época revolucionaria en libros de memoria o textos autobiográficos.

Por otro lado, hay que constatar que los argumentos presentados por los dos críticos para explicar la falta de "la" novela de la Revolución Sandinista entretanto se han vuelto obsoletos. Después de la derrota electoral del FSLN en 1990 Nicaragua experimentó más de una década de gobiernos no sandinistas, e incluso anti-sandinistas, la dominancia del discurso sandinista "oficial” sufrió un gran revés. A partir de mediados de los años ochenta y principalmente en los noventa del siglo pasado y los primeros años de éste,

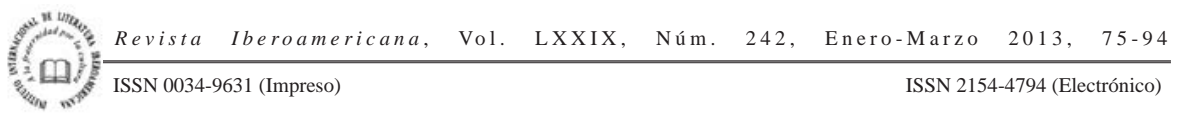


el campo literario nicaragüense ha sido caracterizado por una verdadera proliferación de la novelística -y de la narrativa, en general- (ver Mackenbach, Unbewohnte Utopie 42-47). En este mismo período también ha sido publicado un número significativo de novelas que se refieren exclusiva o principalmente a la década revolucionaria y/o sus antecedentes inmediatos.

De los noventaicinco textos publicados en los años ochenta y noventa que analizo en mi estudio sobre la novela nicaragüense del período, veintidós hacen referencia directa al período revolucionario, es decir, a los años desde el triunfo de la Revolución en 1979 hasta la derrota electoral de los sandinistas en 1990. Si se incluyen los textos que se refieren a los antecedentes, la "prehistoria" de la Revolución, son en total unos treinta (ver Mackenbach, Unbewohnte Utopie 441, 529-33). Para los años 2000 a 2008 el crítico nicaragüense Luis Alberto Tercero ${ }^{2}$ ha contabilizado cuarenticinco novelas nicaragüenses publicadas, de las cuales unas diez hacen referencia al período revolucionario.

Hasta ahora, estas novelas rara vez han sido objeto de estudio de trabajos científicos. Magda Zavala, en su amplio estudio sobre la novela centroamericana terminado en 1990, no se ocupó de esta temática, escribe al final de su investigación que sería necesario "estudiar el ciclo de novelas sobre la revolución en Nicaragua (nicaragüenses y otras) en su relación con la producción testimonial del período" (390). Casi veinte años después esto es todavía un desideratum en el marco de los estudios de las literaturas centroamericanas. ${ }^{3}$ Es recién en los últimos años que se ha comenzado a ocupar del tema. Beatriz Cortez ha estudiado la narrativa en Centroamérica bajo las condiciones de posguerra, especialmente en El Salvador y Guatemala. Ha señalado cómo las coordenadas están cambiando: de la literatura testimonial con su denuncia de las injusticias en el espacio social del campo, especialmente, a una literatura cuyo centro lo constituye la intimidad y subjetividad en el espacio urbano. Esta literatura se distancia y aleja de los proyectos revolucionarios e indaga los lados oscuros de los individuos, sus pasiones, y su frustración por la pérdida de los proyectos utópicos que antes le daban sentido y orientación a su vida en un contexto de violencia y caos:

En contraste con el testimonio, la ficción carece del espíritu idealista que caracterizaba a la literatura centroamericana ligada al contexto de las guerras civiles. Por el contrario, la ficción de posguerra pone frente al lector un espíritu de cinismo. Este tipo de ficción pinta un retrato de las sociedades centroamericanas en caos, inmersas en la violencia y

2 “La novela nicaragüense contemporánea: 2000-2008” (2-3), conferencia presentada en la Universidad de Costa Rica, 12 de noviembre de 2008. Le agradezco a Luis Alberto Tercero haberme facilitado el manuscrito de esta conferencia (no publicada).

3 En mi estudio sobre la novelística nicaragüense de los años ochenta y noventa (Unbewohnte Utopie) dedico todo un capítulo (“Diagonale: Literatur und Revolution” 439-505) al análisis de las novelas nicaragüenses publicadas en ese período que hacen referencia a la Revolución Sandinista.

$\begin{array}{lllll}\text { ISSN 0034-9631 (Impreso) } & \text { ISSN 2154-4794 (Electrónico) }\end{array}$ 
la corrupción. Se trata de sociedades con un doble estándar cuyos habitantes definen y luego ignoran las normas sociales que establecen la decencia, el buen gusto, la moralidad y la buena reputación. (Cortez, Estética 27) ${ }^{4}$

Sin embargo, argumenta Cortez, el cinismo como proyecto estético no es algo completamente negativo, sino que se dedica a la búsqueda de una estrategia de sobrevivencia del individuo en un contexto social marcado por el legado de la violencia y la guerra así como la pérdida de coordenadas fijas de orientación (283-84). La literatura de posguerra es una literatura de desilusión y desenfado, pero también una posibilidad de indagar y experimentar nuevas formas de representación de la intimidad y de la construcción de subjetividad.

Mientras que Cortez se ocupa de textos narrativos de Centroamérica publicados después de los conflictos armados y se concentra en la representación y presentación narrativas de este mundo de posguerra, Seymour Menton se dedica bajo el título "novela postsandinista", en el marco de un proyecto más amplio sobre "narrativa posrevolucionaria" en América Latina, al estudio de las novelas cuyo punto de referencia extraliteraria son los mismos años de la Revolución y los conflictos armados. En particular, analiza la representación de la desilusión en la Revolución Sandinista en algunas novelas de autores nicaragüenses y no nicaragüenses. ${ }^{5}$

Me parece obvio que ni la denominación "estética del cinismo" ni "novela postsandinista” (o "narrativa posrevolucionaria") pueden pretender ser un concepto de la literatura centroamericana en los años noventa. Tienen un carácter más descriptivo, lo que tiene que ver con la poca distancia temporal y el hecho que el mundo de las narrativas centroamericanas de esa época no ha sido explorado ampliamente.

A continuación intento ofrecer para el caso de Nicaragua un panorama de la novela de la revolución en cuanto a la Revolución se convierte en novela, es decir, es ficcionalizada, sin operar con un concepto de "novela de la revolución”. Entonces, la denominación "novela de la revolución” por el momento no quiere decir más que los textos estudiados tienen sus puntos de referencia extraliteraria en los acontecimientos revolucionarios y se presentan en contraposición al testimonio expresamente como

4 También en su ensayo "La verdad y otras ficciones: visiones críticas sobre el testimonio centroamericano" la autora se ocupa de esta temática. En ambos ensayos analiza textos narrativos (novelas y cuentos) de Salvador Canjura, Claudia Hernández y Rafael Menjívar Ochoa de El Salvador, del hondureñosalvadoreño Horacio Castellanos Moya y del guatemalteco Rodrigo Rey Rosa.

5 Me refiero a su texto "Sol y sombra: la novela postsandinista" presentado como ponencia en el VIII ${ }^{\circ}$ Congreso Internacional de Literatura Centroamericana (Antigua, Guatemala, 1-3 de marzo de 2000). En este texto, Menton analiza las novelas Un sol sobre Managua (1998), de Erick Aguirre, y La lotería de San Jorge (1995), del escritor mexicano Álvaro Uribe. Le agradezco a Seymour Menton por haberme facilitado el manuscrito de esta ponencia. Ver también su ensayo "La novela postsandinista: Un sol sobre Managua y La lotería de San Jorge” (2000).

$\begin{array}{llllll}\text { Revista Iberoamericana, Vol. LXXIX, Núm. 242, } & \text { Enero-Marzo 2013, } & \text { 75-94 } \\ \text { ISSN 0034-9631 (Impreso) }\end{array}$ 
ficción (sin diferenciarse mucho de él en cuanto a su temática). ${ }^{6}$ Este análisis incluye textos que fueron escritos antes, durante y después de los años del gobierno sandinista y que tienen como puntos de referencia extraliteraria la década revolucionaria, sus antecedentes inmediatos y sus consecuencias directas.

\section{LA REVOLUCIÓN COMO METÁFORA}

En mi estudio sobre la novelística nicaragüense de las últimas dos décadas del siglo $\mathrm{xx}$ he intentado una primera conceptualización de las novelas que se refieren a la revolución, con base en su semantización metafórica. Entre otros, he identificado los siguientes procedimientos de metaforización: la revolución como resultado de una prehistoria (casi) desconocida y reprimida, la revolución como una guerra fratricida irreconciliable, la revolución como una fuerza natural incontenible, la revolución como una memoria indeseada, la revolución como un museo no construido, la revolución como un amor no realizado, la revolución como un lenguaje inestimado, la revolución como un conflicto social irresuelto, la revolución como un pasado no superado, la revolución como una utopía deshabitada (ver Mackenbach, Unbewohnte Utopie 444-503).

Así, por ejemplo, en su novela En el umbral de los sueños (1998), que en la solapa de la contraportada es caracterizada como “ficción con un fondo de realidad”, René Quesada esboza una imagen de la "Escuela de Ingeniería” en la Calle Colón de Managua de los años cincuenta del siglo xx. Sus protagonistas son personajes que hacen referencia a los profesores y estudiantes de esta primera escuela superior de ingeniería en Nicaragua. Esta escuela es metaforizada como una sinécdoque de la casi desconocida prehistoria de la Revolución: el proceso de concientización política a finales de los años cincuenta. La agitación política del estudiantado y profesorado de la institución es parte de un proceso mucho más amplio de cambio político y social que comienza con la revolución en América Latina y tiene fuertes repercusiones y raíces propias en Nicaragua:

[...] se había dado el derrocamiento de Batista en Cuba y comenzaría para Nicaragua una experiencia nunca vivida antes con la presencia de la naciente revolución Castrista, que poco a poco extendería sus tentáculos de violencia por todo el continente. Conocería Nicaragua estupefacta la aparición del “Coctel Molotov” y las intrigas de embajada en la persona del embajador de Cuba Quintín Pino Machado. El país entró poco a poco en la vorágine de la actividad revolucionaria y de la subversión. El Ché Guevara empezaba a convertirse en una leyenda. (Quesada 203)

6 Los primeros resultados de mis pesquisas sobre estos textos fueron publicados en el ensayo "La utopía deshabitada. La 'década sandinista’ en tres novelas nicaragüenses de los años noventa” (ver también Mackenbach "Unbewohnte Utopie”, "Literatura light” y "Novela de posguerra”). Acerca de dos autores salvadoreños y guatemaletcos ver Mackenbach, “Zum Weiterleben” y “Hinkende”.

\footnotetext{
ISSN 2154-4794 (Electrónico)
ISSN 0034-9631 (Impreso)
} 
Este proceso (pre)revolucionario irrumpe en la vida cotidiana de los nicaragüenses como una fuerza natural que nadie y nada puede contener. En la novela Atentado en el río, de Julio Centeno Gómez, uno de los protagonistas, Marco Antonio, se imagina en uno de sus sueños cómo se levanta un huracán, ataca a la gente reunida en las plazas, arranca los árboles y se lleva los techos:

[...] y una voz tronó en la inmensidad del cielo diciendo: Soy el viento de la revolución, vengo desde las heladas estepas siberianas y las cumbres de los urales, azoté las misteriosas pagodas chinas, penetré las abigarradas urbes de Europa Oriental y el vasto territorio de los Aztecas; sacudí el Continente negro en sus largas y misteriosas noches tribales; estremecí el Caribe barriendo los garitos de las Islas Antillanas, estoy en Nicaragua azotando sus lagos y volcanes, derribando dinastías y cacicazgos. (159)

Esta fuerza natural también arrastra a los revolucionarios mismos:

El viento seguía tronando, llevándose todo por los aires, los papeles volaban sobre las ruinas de las casas y un gran remolino envolvió a los caudillos de la revolución y los hizo volar muy alto como hojas secas, tan alto que quedaron por momentos brillando frente al sol para después precipitarse a tierra en vertiginosa picada [...]. (Centeno Gómez 159)

También en la novela Sábado de gloria, de Orlando Núñez Soto, que hace referencia a los primeros, todavía “inocentes” días de la Revolución, antes de la entrada triunfal de los revolucionarios a la capital, la Revolución irrumpe en la vida de los habitantes de la ciudad y el campo y descompone las relaciones existentes. Sin embargo, al mismo tiempo las sombras del pasado pesan como una pesadilla sobre ellos. El día de la liberación parece ser un "corto y largo sábado de gloria” (189) -así el título de la novela- y la vida en la ciudad como una serie de procesiones de Semana Santa. Pero ya ese mismo día del triunfo la alegría general es contaminada por una sensación de inseguridad y amenaza. Casi todas las casas están en ruinas, en las iglesias están reunidos miles de niños que huyeron del fuego cruzado de la ofensiva final, las puertas de las iglesias están cerradas, sin embargo, se olfatea el olor a cadáver que emana y cubre toda la ciudad (ver $5,8,28)$. El proceso de revolución y cambio social apenas ha comenzado; se anuncia una nueva guerra, más difícil y lenta que la lucha para el derrocamiento del dictador:

En ese momento ya la cara de la dictadura dejaba de ser la Guardia Nacional, para tomar cuerpo en toda la historia de sus propias vidas, y la lucha contra los cuarteles parecía desdoblarse en una lucha mayor contra un ejército de fantasmas y culpas que hasta entonces no habían presentado armas contra la chavalada insurrecta [...]. (Núñez Soto 85)

$\begin{array}{llllll}\text { ISSN 2154-4794 (Electrónico) } & \text { Revista Iberoamericana, Vol. LXXIX, Núm. 242, }\end{array}$ 
Estas fuerzas tienen sus repercusiones hasta en la historia más íntima de los dos protagonistas, Claudia y Marcos. Claudia, quien es mucho mayor que Marcos y su superiora en el "Comando Central del Frente Norte", se enamora de él y es correspondida -ésta es una relación que rompe con los patrones tradicionales, posibilitada por los tiempos revolucionarios-. Pero las sombras del pasado se apropian de esta relación. Por medio de la madre de Claudia y del padre del pueblo los dos saben que Marcos es el hijo de la misma Claudia, fruto de una violación de Claudia por el comandante de la Guardia Nacional, Coronel Pancho Ruiz, que también violó a la madre de Claudia, Chabela, y por eso también es padre de Claudia. Con este motivo de la doble violación y del incesto el autor logra una alegoría de la sobrevivencia de las viejas estructuras hasta en las relaciones más íntimas de las personas. Aunque la Revolución ha impactado en las relaciones tradicionales como una fuerza natural, también las fuerzas prerrevolucionarias tienen su impacto independientemente de la voluntad de los actores y condicionan su libertad de decisión.

En la novela Tu fantasma, Julián Mónica Zalaquett semantiza la Revolución como una guerra fratricida irreconciliable, personalizada en los dos hermanos, Julián y José Benito, que militan en los dos bandos opuestos del conflicto. Julián está comprometido con la Revolución como funcionario sandinista, José Benito se transforma en el líder de un grupo contrarrevolucionario que asesina a Julián. Muy representativamente para el país en total, la familia es dividida y destruida por el conflicto.

El valor particular de la novela radica en el hecho que no toma posición por ninguno de los dos bandos y se enfoca en el interés de los campesinos pobres a no ser forzados a apoyar a ninguno de los dos partidos del conflicto, los sandinistas y los contras, para poder vivir en paz. Con esta mirada crítica de las repercusiones de la Revolución Sandinista y la guerra de la contra en una familia campesina la novela apunta a un cuestionamiento de la Revolución. No es la tan evocada intervención extranjera del Big Brother en el Norte la que es responsable del fracaso de la Revolución (aunque reconoce ampliamente la importancia de este aspecto), sino sus contradicciones internas, la incomprensión de un sandinismo urbano y de sus cuadros dirigentes para con la vida rural y los intereses campesinos (ver Hood 105). ${ }^{7}$ La novela puede ser leída como una alegoría de la contradicción fundamental de la Revolución Sandinista y de las causas

\footnotetext{
7 En una entrevista que realizó Edward Waters Hood, Mónica Zalaquett se refiere explícitamente a este aspecto y al trasfondo autobiográfico de la novela: "Yo llego (al campo), y la vida con ellos (los campesinos) me enseñó a respetar las tradiciones y los valores de la gente, y a conocer mi realidad y respetar mi realidad y darme cuenta de que realmente nosotros no podemos llegar a imponer algo a la gente porque creemos que va a ser bueno, sino que la gente tiene que pedirlo, y desearlo y necesitarlo. [...] Nuestra revolución no entendió el problema de las tradiciones y los valores del campesino porque nuestra revolución no era una campesina; era una revolución urbana, y el problema es que Nicaragua es un país rural” (Hood 104).
}

\footnotetext{
$\begin{array}{llllll}\text { ISSN 2154-4794 (Electrónico) } & \text { Revista Iberoamericana, Vol. LXXIX, Núm. 242, }\end{array}$
} 
de su fracaso, publicada en una situación en la que en el discurso político apenas se escuchaban voces que formularan críticas parecidas y también dejaran sus huellas en la literatura testimonial, ${ }^{8}$ mucho antes de que esta perspectiva fuera tematizada en las memorias de conocidos líderes sandinistas. ${ }^{9}$

Los dos hermanos enemistados, Julián y José Benito, hasta en su guerra fratricida irreconciliable están ligados y aferrados el uno al otro: “Quién soy entonces?” se pregunta Benito en la última parte de la novela y se auto-contesta: "Tu fantasma, Julián [...], un fantasma desgraciado" (184). El monstruo Revolución no solamente los devora a los dos: "Nos jodieron -tragó con dolor- y nosotros nos dejamos", añade Benito (184). En su dualidad, a ambos los une una identidad mucho más remota y profunda que se nutre de la historia mitificada de su pueblo: en una conversación José Benito dice "que una vez, hacía muchas lunas, los piratas habían invadido el pueblo, que era en aquel entonces una gran ciudad” (96) en cuyos ríos corría más oro que agua. Julián le cuenta al jefe de su tropa: "la historia de ese pueblo que había sido una gran ciudad, antes que llegaran a destruirla unos piratas desalmados", para que "entiendan a esta gente y sepan por qué se alzaron" (193-94). Este pasado compartido y míticamente evocado es completado por la concepción de un "doble yo", una dualidad metafísica como rasgo característico de los nicaragüenses, que se vale de la concepción de "el nicaragüense" del poeta Pablo Antonio Cuadra. En su ensayo "Los hijos de Septiembre”, Cuadra describe al ser humano nicaragüense en alusión a las esculturas prehispánicas en la isla Zapatera en el Lago de Nicaragua como "un ser dual con dos mitades dialogantes y beligerantes" (16) e interpreta la historia de Nicaragua, especialmente la larga tradición de las guerras civiles hasta la Revolución Sandinista y la guerra de la contra, como expresión de una “concepción mítica y misteriosa del 'doble yo' o 'alter ego vital' [...] que produjo Nicaragua” (16-17). Este recurso a uno de los intelectuales enemigos de la Revolución más conocidos inmediatamente después de la derrota de los sandinistas en 1990 le añade otro rasgo provocador a la novela de Mónica Zalaquett.

Al igual que Mónica Zalaquett, en su novela Vuelo de cuervos Erick Blandón se refiere a uno de los acontecimientos más significativos dentro del proceso políticosocial que se inició con la revolución del 19 de julio de 1979: la evacuación de los indios miskitos de sus territorios tradicionales en la región del Caribe nicaragüense por el gobierno sandinista al inicio de los años ochenta para presuntamente integrar a los miskitos al resto de la civilización y al mismo tiempo privar a la contra de una parte de su apoyo social entre el campesinado.

8 Ver especialmente el libro Una tragedia campesina: testimonios de la resistencia, de Alejandro Bendaña Rodríguez, publicado en 1991, que reúne testimonios de campesinos que lucharon en la contra antisandinista.

9 Ver especialmente Adiós muchachos. Una memoria de la revolución sandinista, de Sergio Ramírez, publicado en 1999.

$\begin{array}{llllll}\text { ISSN 2154-4794 (Electrónico) } & \text { Revista Iberoamericana, Vol. LXXIX, Núm. 242, }\end{array}$ 
Con esto, Erick Blandón logra una deconstrucción literaria de la Revolución Sandinista demostrando cómo-principalmente en el actuar de los cuadros intermedios-las mejores intenciones revolucionarias se convierten primero en farsas después en tragedias políticas, ya sea por falta de experiencia, anhelos de mantener el poder a cualquier costo o por obediencia ciega a un aparato estatal-partidario que se ha alejado del pueblo más humilde. Sin embargo, la novela no se limita a esta deconstrucción de la Revolución. Se ocupa de la relación entre los intelectuales y el poder-una problemática omnipresente en la política latinoamericana más reciente, y especialmente en la Nicaragua de la década de los ochenta-. Al inicio de la novela, Laborío -“yo, pequeño burgués graduado en la universidad, dándose la gran vida en el extranjero mientras los verdaderos revolucionarios se quedaron arriesgando el pellejo, combatiendo a la guardia" (25)-recibe el encargo de escribir la "memoria" de la evacuación. Lleno de orgullo de esta misión revolucionaria especial se va de viaje llevando un "secreto militar", un mensaje del coronel Pulido al subcomandante Mendiola (3). Al final de la novela esta correspondencia importante manifiesta su verdadero carácter, en el papel dice:

El portador es un vago de mierda que aquí sólo para estorbo sirve, él cree que este es un mensaje altamente confidencial; y espera que usted le dé orientaciones de cómo escribir la memoria de esta misión. Hágale sentir la rudeza de la vida militar a ver si así salimos de él. Póngalo a hacer cualquier cosa y que no se aparezca en mucho tiempo por aquí. Que siga creyendo que su misión es de suma importancia. (Zalaquett, Vuelos 271-72)

La crónica de la acción se convierte en una memoria no deseada, símbolo de los intentos de borrar los recuerdos de los lados oscuros del proceso revolucionario.

También la novela Debió llamarse libertad, de Georgina Lupiac, remonta a una de las contradicciones fundamentales del proceso revolucionario: el obligatorio Servicio Militar Patriótico (SMP), establecido en 1983, sin lugar a dudas uno de los factores decisivos para la pérdida de una gran parte de la base social del gobierno sandinista y la derrota electoral del FSLN. Esta historia se cuenta en gran parte como un viaje: la huida de Sabina, única hija de una familia de clase media, inicialmente comprometida con la Revolución, que después pierde la confianza en el proceso revolucionario por el rumbo que toma. Al final no solamente termina en un refugio en otro país bajo otras condiciones políticas, sino también en un mundo de otros valores ideológicos, encontrando la paz en Dios. Como trasfondo, esta historia de un amor no realizado, que al mismo tiempo es la historia de una confianza perdida (en la Revolución) y de una fe recuperada (en Dios), se refiere a los acontecimientos de los años entre la caída de la dictadura de 1979 hasta la segunda mitad de los años ochenta: la toma de poder por la junta de gobierno, la renuncia de Violeta Barrios de Chamorro y Alfonso Robelo de este gobierno, el caso

\footnotetext{
Revista Iberoamericana, Vol. LXXIX, Núm. 242,
ISSN 0034-9631 (Impreso)
} 
Carballo, ${ }^{10}$ el reclutamiento para el SMP, la confrontación entre gobierno e Iglesia, la guerra con la contra y los campamentos de los refugiados en Honduras.

En contraposición a muchas novelas que se refieren a la Revolución, Waslala. Memorial del futuro, de Gioconda Belli, con la excepción de varias alusiones, no se basa en hechos o datos históricos del proceso revolucionario, sino trata de reconstruir/ mantener el "espíritu” de la Revolución, su contenido utópico. Tematiza la sobrevivencia de la utopía revolucionaria bajo condiciones posrevolucionarias. La leyenda del mítico y utópico lugar, Waslala, que hace mucho tiempo fue fundado por un grupo de poetas, se ha quedado viva aunque el país en general al inicio del tercer milenio se ha convertido en el escenario de guerras endémicas, del narcotráfico internacional, de la represión política, del tráfico de niños, de catástrofes ecológicas, etc. Tal vez Gioconda Belli haya querido escribir "la gran novela" de la revolución cuya no existencia ha sido lamentada por la crítica, como mencioné al inicio de este ensayo. En la búsqueda del mítico Waslala -una especie de república de poetas-, donde se presume han sobrevivido la idea y los ideales de la Revolución, se simboliza la fe en la persistencia del proyecto revolucionario. Gioconda Belli recurre a los elementos utópicos-míticos del nacionalismo literario de la década sandinista, con la diferencia que no quiere repetir los "errores" de este proyecto. Pero Waslala no tiene que ver nada con Waslala, es decir, la integración fallida de los indios/campesinos al proyecto revolucionario. ${ }^{11}$ Este problema no tiene cabida, de ninguna manera, en el argumento de la novela. "Waslala" es un lugar mítico, idílico, estéril e inverosímil, sin existencia terrenal, incluso sin habitantes: una utopía deshabitada.

\section{SEMANTIZACIONES HISTÓRICAS DE LA REVOLUCIÓN}

Si ampliamos el análisis de la semantización de las representaciones literarias de la Revolución en relación con los conceptos de historia subyacentes, el panorama ofrece igualmente una gran variedad. Especialmente, los libros publicados por algunos de los

${ }^{10}$ El 11 de agosto de 1982, en uno de los incidentes conflictivos más espectaculares entre el sandinismo y la Iglesia Católica, el sacerdote Bismarck Carballo fue invitado a almorzar en la casa de una feligresa en Managua. Un hombre ingresó a la vivienda, lo golpeó, realizó disparos y lo obligó a desnudarse. Después apareció la Policía Sandinista y lo sacó a la calle, donde grupos de sandinistas lo esperaban y periodistas de la prensa oficialista lo grabaron y fotografiaron para luego difundir las imágenes montando una relación entre el sacerdote y la dueña de casa.

11 Ya Ernesto Cardenal había estilizado Waslala como mito revolucionario sin problematizar el rechazo de la Revolución por los indígenas que viven allá. Para una crítica de esta "estilización” de Waslala en la poesía de Ernesto Cardenal ver Beverley y Zimmerman (103-4, 113). En los años noventa Waslala se transformó en uno de los pueblos que sufrieron de una manera muy directa de las consecuencias de la guerra contra la contra. Se sumergió en extrema pobreza y tuvo una de las tasas más altas de delincuencia en Nicaragua (ver Mackenbach, "Waslala” 37-38).

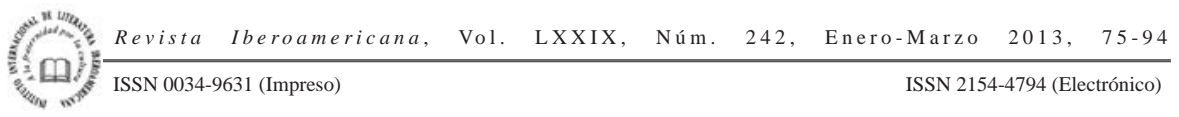


antaño líderes del movimiento revolucionario en los años después del fin del gobierno sandinista muestran que en la "batalla de la memoria" mencionada al inicio de este ensayo recurren a semantizaciones históricas que se nutren de discursos y visiones del mundo extraliterario de diferente índole.

El libro La epopeya de la insurrección, de Humberto Ortega, ex-jefe del Ejército Popular Sandinista, no es una novela, sino que se presenta como un gran relato del movimiento revolucionario, de las "Raíces” (capítulo I) a "La insurrección victoriosa” (capítulo VI); sin embargo, recurre a muchos elementos de ficcionalización. Ya el paratexto del título reclama en su evocación de la architextualidad literaria ("la epopeya”) una autoridad de lo relatado que se pronuncia aún más por la reclamada autoría del texto: no es el hombre, escritor o ciudadano Humberto Ortega que se presenta como autor, sino el "General Humberto Ortega Saavedra”. Con eso, ya desde la portada el texto pretende una autoridad máxima en la interpretación de la historia reciente -e incluso la más remota- de Nicaragua, una especie de posicionamiento, si no oficial, por lo menos oficioso. Construye la Revolución Sandinista como resultado lógico de un desarrollo personal e histórico-social. Desde la infancia y juventud del narrador-protagonista a la Revolución como acontecimiento social, el texto está marcado por una concepción "progresista” y "desarrollista” de la historia.

De manera representativa de muchos participantes y líderes de la Revolución, construye sus orígenes personales en el seno de una familia (casi) proletaria y con largas tradiciones "rebeldes" de parte de su abuelo paterno y su padre que después de vivir en Chontales, en la Libertad, “pequeño pueblo minero” (Ortega, Epopeya 35), migra para la capital. El texto evoca estas raíces proletarias -e indígenas- ya en el primer párrafo del primer capítulo, haciendo referencia a la historia del lugar:

Este poblado no era muy diferente de como fue descrito a finales del siglo xix: un centro de nueve ricas minas de oro que, en 1889, tenía dos mil quinientos habitantes, entre ellos indígenas que se ocupaban de la producción minera, la cual trasladaban por el único camino existente allí y que lo comunicaba con San Ubaldo, puerto en el lago de Nicaragua, distante a 65 kilómetros. (35)

De su familia destaca el activismo político:

Mis padres y mi abuelo son parte activa de una época en la historia de Nicaragua, la de los años de la intervención norteamericana -1912-1933-; la de las migraciones masivas de nicaragüenses, mestizos e indígenas del Pacífico a las tierras de Chontales, la antigua frontera colonial que dividía a nuestro país entre Pacífico y Atlántico o Caribe. Mi padre, don Daniel Simeón Ortega Cerda, nació en 1905 [... ]. Desde joven fue rebelde [...]. Mi abuelo hizo contribuciones muy importantes a la educación nicaragüense, a través del ejercicio de la docencia en el Instituto Nacional de Oriente; también aporta

\footnotetext{
ISSN 2154-4794 (Electrónico)
ISSN 0034-9631 (Impreso)
} 


\begin{abstract}
a la política de su época, a través de su accionar en el Partido Conservador, durante la década de 1920. (35-36)

[...]

Don Daniel era admirador de la Sociedad Teosófica de Madama Blavatsky. Sus ideas políticas fueron motivadas por el liberalismo de los años veinte: la noción de progreso, el amor a la patria y la necesidad de actuar por la libertad y ante las situaciones de injusticia; fue un ferviente admirador de Augusto C. Sandino [...]. (37-38)
\end{abstract}

Sin embargo, la Revolución Sandinista es mucho más que un resultado de este activismo político individual y colectivo. Es el eslabón lógico en una larga cadena de ciclos históricos. "Toda incomprensión del presente, surge de un desconocimiento del pasado”, reza la primera oración del libro (23), y el autor continúa que con su texto “al hurgar en el ayer procura dar elementos para entenderlo mejor y así juzgarlo sabia y justamente” (23). La revolución en Nicaragua es construida como un punto culminante del último ciclo de la evolución de la historia:

[...] como un medio para facilitar la comprensión de la evolución de nuestro proceso histórico, este lo divido en los Ciclos siguientes:

- Ciclo del Origen Remoto y Prehispánico

- Ciclo del Descubrimiento, Conquista y Colonia

- Ciclo de la Independencia y la Formación del Estado-Nación

- Ciclo del Protectorado Norteamericano y la Resistencia Armada

- Ciclo Histórico de la Dictadura Militar de los Somoza

- Ciclo Histórico de la Democracia. (Ortega, Epopeya 24, énfasis del original; ver también 23 y 25-28)

Estos ciclos, por su parte, se insertan en una evolución histórica mayor, resultando en “El Mural 'Por un mundo mejor "” (ver 471-74) que se anexa al libro, una especie de crónica de la historia del mundo y de la humanidad en cuarentaiséis estaciones que "expresa mis sentimientos más hondos, acerca de la enigmática existencia en la dilatada historia del universo" (23, énfasis del original), desde "1- Hace 16 Mil MA - Millones Años - El Cataclismo, Gran Explosión” (473, énfasis del original) a “46- Globalización” (475, énfasis del original) pasando por "45- Nicaragua”:

Conquista - Colonia - Independencia 1821 - guerras civiles - Filibusteros - Bases Estado moderno - conservadores y liberales - Siglo xx protectorado militar norteamericano guerra de resistencia - dictadura militar e insurrección - revolución y contrarrevolución - guerra y paz - polarización y pobreza - El Presente: integración o miseria - Desarrollo democracia - Utopía - Felicidad. (475, énfasis del original)

La revolución sandinista es, entonces, ni más ni menos que la perfección de un desarrollo histórico, el resultado de un continuismo pasado-presente-futuro progresivo que obedece

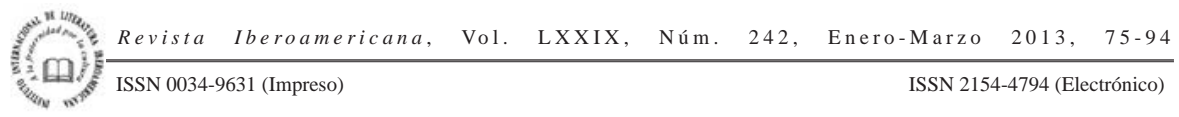


a leyes generales y que lleva lógicamente a la "felicidad"-una justificación ahistórica inapelable-.

En la ya mencionada novela Waslala. Memorial del futuro, de Gioconda Belli, el pasado es construido en función del futuro-un futuro en el que se realiza la utopía perdida y traicionada en el presente. Con esto, la autora recurre a unos rasgos fundamentales del Romanticismo en Europa. Como la novela del Romanticismo europeo de finales del siglo xvir/inicios del siglo xIx, Waslala se basa en un -casi idílico-relato de viaje, un tipo de prosa muy divulgado dentro del Romanticismo. Como en el Romanticismo, la utopía es un lugar concreto que se encuentra al final del viaje aventurero. Gioconda Belli, como los autores románticos, relata la búsqueda de la utopía como la recuperación de la "era dorada", de un pasado idílico (hasta el subtítulo de la novela evoca esta relación: "Memorial del futuro”). Como en la novela romántica alemana (especialmente en Heinrich von Ofterdingen de Novalis y Aus dem Leben eines Taugenichts, de von Eichendorff) se fusionan el (ante)pasado y el futuro, hombre/mujer y naturaleza/tierra en una infinidad de tiempo y espacio, una "distorsión del espacio-tiempo", como se dice en la novela misma: "Waslala existe en un interregno, una ranura del tiempo, un espacio indeterminado" (Belli, Waslala 366). Como ya en sus novelas La mujer habitada y Sofía de los presagios la autora construye el pasado mítico -valiéndose de y reinterpretando los mitos y leyendas prehispánicos- en función de un proyecto utópico que se realizará en el futuro, sin (pre)ocuparse de las distopías en el presente.

En su libro Vida perdida. Memorias Tomo I y en los siguientes tomos de sus memorias (Las ínsulas extrañas. Memorias Tomo II; La revolución perdida. Memorias Tomo III; Los años de Granada: Continuación de la vida perdida, Ernesto Cardenal cuenta su concientización y la emergencia del movimiento revolucionario como la realización terrenal de una fuerza mayor - del más allá cristiano que se construye en el aquí y ahora sobre la tierra-. Como no es el autor Ernesto Cardenal que escribe estas memorias, sino "Dios, que es el que de alguna manera escribe por mí, o dirige lo que yo escribo en cierto modo" (Vida 24), no son los hombres y mujeres que hacen la revolución como seres humanos comunes y corrientes, sino como seres perdidos -y salvados- en la fe en Dios, siendo el amor divino la verdadera fuerza motriz que mueve la historia y le da un carácter escatológico. La vida humana está perdida y reencontrada en un proyecto colectivo sobrehumano trascendente, teleológico y escatológico. Así, casi programáticamente termina el libro con un epílogo:

Quien me hizo tomar un avión para ir a encerrar mi vida entre los muros de un monasterio en los Estados Unidos, me sacó después de allí y me llevó al aislamiento de una isla del archipiélago de Solentiname, y después a la participación en una revolución. Espero en vos, Amor, que esta vida, en más de un sentido perdida, sea después de todo una vida ganada. (Vida 455)

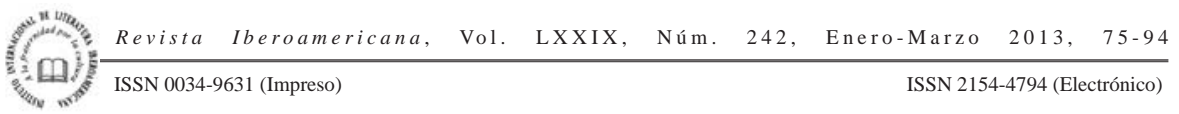


En su novela Sombras nada más Sergio Ramírez por primera vez en su novelística se refiere no solamente a los antecedentes y la prehistoria de la Revolución, sino al proceso revolucionario en el momento del triunfo sandinista mismo. Esta novela cuenta la historia de un alto ex-funcionario somocista, Alirio Martinica (que hace referencia directa al personaje histórico Cornelio Hüeck), que llega a ser secretario del dictador y confidente de su amante. Es un hombre todopoderoso que queda en la sombra y un día es apartado del poder. A diferencia de otros somocistas, decide no huir y es capturado por los guerrilleros pocos días antes del triunfo de la Revolución en 1979. Es sometido a un interrogatorio y después a un juicio popular en el que es condenado a morir frente a un pelotón de fusilamiento. En contra de la buena voluntad de los guerrilleros -"Ese tribunal, lo que es ahora mismo, ni siquiera existe, se va a formar hasta mañana, y además, como las mismas palabras lo dicen, va a ser un tribunal de averiguaciones, no para sentencia” (111), dice uno de los interrogadores- y los ideales de la revolución _"Por la Radio Sandino, la radio clandestina de los guerrilleros que él [Alirio Martinica] sintonizaba cada noche, con miedo y curiosidad, siempre estaban repitiendo que ésta iba a ser una revolución humanista, sin paredón, y que se garantizaba la vida a todos los que se rindieran" (18-19)- el proceso revolucionario que se desata con el incipiente triunfo obedece a otras fuerzas que se imponen a espaldas de los actores humanos.

Una vez suelta la dinámica revolucionaria, el poder se impone a través de las masas agitadas que como espectadores participan del tribunal. Al estilo del coro en la tragedia clásica intervienen en los acontecimientos:

[...] se vio venir de lejos una multitud desbocada, estallaban cohetes y bombas de mecate, música revolucionaria atronaba en los parlantes de una barata que rebasaba por el tropel se acercaba cargada de niños en la trompa y en los estribos [...] se habían bajado los guerrilleros de los camiones y su bandera se perdía ahora entre las otras banderas, rojo y negro por todas partes, se alzaban los fusiles al ritmo de una consigna que costaba distinguir desde el encierro de la cabina, uno tras otro los rostros se aplastaban contra la ventanilla y había puños que golpeaban la capota, uñas que arañaban en vano, una mujer de luto, seca, cetrina, había lanzado un escupitajo y la saliva resbalaba sobre el vidrio. ¡Paredón! ¡Paredón! ¡Paredón!, entendió al fin la consigna que cantaba el coro al mismo compás con que los puños pegaban sobre la capota y se alzaban los fusiles [...]. (Ramírez, Sombras 183)

Finalmente, la ejecución es representada con recursos carnavalescos:

Lo llevaron a fusilar en calzoncillos y camisola. [...]

En la calle esperaba una gran jaula, de esas para poner adentro lapas, loras, tucanes, toda clase de pájaros de plumaje vistoso, tan grande que dentro alcanzaba perfectamente un hombre, aunque algo encogido [...]. Entonces, entre alegrías de música y festejos de

$\begin{array}{llllll}\text { ISSN 2154-4794 (Electrónico) } & \text { Revista Iberoamericana, Vol. LXXIX, Núm. 242, }\end{array}$ 
pólvora, fue metido a la jaula, y ya con él adentro la cargaron a pulso hasta ponerla en la tina de una camioneta de acarreo para el desfile al cementerio, el gentío derramado en el trayecto [...].

Después vino el fusilamiento [...]. (398-99)

Un fatalismo histórico se adueña de los acontecimientos, la historia aplasta a los contemporáneos como una rueda despiadada, el pasado pesa sobre el presente e impide un futuro que se libere del peso de las estructuras viejas.

En una entrevista Sergio Ramírez comentó a este respecto:

\begin{abstract}
¿El poder? El poder me fascina, es un juego perverso y apasionante [...]. Sus reglas, trampas y oscuridades son milenarias. No cambian. Pueden aplicarse a cualquier sistema político. Nadie [...] puede negar el poder del poder. Es una fuerza del destino que se puede manipular. Los tres guerrilleros que en la novela atrapan a Alirio Martinica están jugando al poder, juegan al poder sobre el poderoso, y es fascinante ver cómo el poder mueve y cambia las vidas de las personas aunque las personas no lo quieran. El poder me sirve para desmitificar a los personajes. Eso que nos hace suponer que un guerrillero que baja de la montaña sea un santo cuando los guerrilleros también son seres humanos y también capaces de cualquier cosa. (Fernández-Santos)
\end{abstract}

La revolución termina -ya en el momento de su triunfo-regresando a los viejos métodos, como ya se insinúa paratextualmente en el epígrafe de la novela:

Fortuna ya me enseñó antes su gran fuerza y poder. Ya me enseñó cómo mueve, con un giro de su rueda, al mundo entero. Al mundo entero lleva dando vueltas, y vigila con la mirada el giro de cada uno. Quienes están sentados arriba en su rueda, ignoran lo que les va a tocar en suerte: caer a sus pies, en la desgracia, heridos de vergüenza, cansancio y dolor. Ahora en la cumbre, luego precipitados en la caída... Philippe de Rémi, La doncella manca. (Ramírez, Sombras 9)

En resumen, las obras mencionadas basan sus construcciones de mundos literarios en discursos extraliterarios que representan algunas de las fuerzas motrices del proceso revolucionario en Nicaragua que -como todas las revoluciones en la historia- se nutrió de tendencias e intereses muy diversos, contradictorios e incluso contrapuestos.

\title{
LA BATALLA DE LA MEMORIA Y LA LITERATURA
}

El panorama presentado de las novelas nicaragüenses que hacen referencia a la revolución sandinista de 1979 señala que no es posible hablar de una novela de la revolución en un sentido estrecho. La novela de la revolución como vista total o totalizante de los acontecimientos revolucionarios, sus antecedentes y de sus fuerzas motrices inherentes

\footnotetext{
Revista Iberoamericana, Vol. LXXIX, Núm. 242,
ISSN 0034-9631 (Impreso)
} 
no existe. También para la representación de la Revolución Nicaragüense se puede resumir, lo que Fernando Alegría escribió acerca de la novela de la Revolución Mexicana:

\begin{abstract}
Si reconocemos en la Revolución Mexicana un proceso histórico cuyas proyecciones superan el límite temporal de las circunstancias políticas de una época determinada habremos de aceptar como características de la Revolución no sólo a las novelas de acción guerrera, sino también a aquellas que interpretan la periferia del hecho histórico y lo sondean en planos psicológicos, filosóficos o sociales.

[...]

Lo político y lo no-político, lo trascendente y lo episódico, como las puntas de una hélice giran vertiginosamente alrededor de un centro común, pero aunque van en la misma dirección tocan una atmósfera que nunca es la misma y el círculo que cierran está hecho de un infinito en que verdaderamente no se encontrarán jamás. (130-31)
\end{abstract}

Como Alegría presenta la novela de la Revolución Mexicana en forma de un árbol genealógico con las más diversas ramificaciones, ${ }^{12}$ así las novelas sobre la Revolución Sandinista las caracteriza no sólo temáticamente una amplia gama de variedad similar -de los antecedentes de la Revolución en sentido más amplio a los acontecimientos revolucionarios en sentido estrecho, hasta las repercusiones y consecuencias de la Revolución, la guerra y la guerra civil; de la mirada a los sucesos en el centro del proceso revolucionario a su continuación y sus raíces en los márgenes hasta sus repercusiones en el extranjero y el exilio; de la focalización en los acontecimientos "exteriores" a la ocupación con la psicología de los grupos sociales involucrados en la Revolución, hasta el sondeo de la vida interior de los individuos afectados por la Revolución-.

También la representación y presentación narrativas de la Revolución son caracterizadas por una variedad formal. La "novela de la revolución” se presenta como novela filosófica, como sátira, caricatura y parodia, como novela cursi y panfleto, trabaja con elementos de la novela del dictador y la novela histórica, con recursos irónicos y de carnavalización, recurre a formas y estructuras narrativas tradicionales, utiliza técnicas experimentales, mezcla elementos mágicos con autobiográficos y periodísticos, así como métodos de ficción/representación mimética, no mimética y anti-mimética.

Obviamente, esta diversidad no permite llegar a un concepto único u homogéneo de la novela de la revolución. Las novelas publicadas en los años noventa tampoco se prestan para una caracterización como literatura posrevolucionaria (más allá del aspecto temporal de su publicación) o como "estética del cinismo", porque no se puede

${ }^{12}$ Habla expresamente de un "brote indianista" (para la diferenciación entre indianismo e indigenismo ver Rössner 182, 353, y el capítulo “Zweiter Kreis: Magie und Realität” de Mackenbach, Unbewohnte Utopie, 168-70, 205-9), una tendencia de protesta social, narraciones picarescas, que se ocupan de las repercusiones de la revolución en la provincia, una "meditación barroca", la "novela de los Cristeros" y obras que tienen un carácter más histórico que literario (Alegría 31).

$\begin{array}{llllll}\text { Revista Iberoamericana, Vol. LXXIX, Núm. 242, } & \text { Enero-Marzo 2013, } & \text { 75-94 } \\ \text { ISSN 0034-9631 (Impreso) }\end{array}$ 
constatar una ausencia generalizada de rasgos idealistas o un alejamiento definitivo de las premisas político-ideológicas en que se ha basado el proyecto revolucionario (que en algunas novelas se reflejan hasta en su rechazo riguroso). La novela de la revolución nicaraguense presenta a la revolución como novela, como un texto no terminado/ concluido, en principio como un texto infinito. Esta diversidad y complejidad se ensambla en el mosaico de los cambios sociales y políticos en la Nicaragua de los años setenta, ochenta y noventa, de sus contradicciones, problemas y absurdidades, que incluso puede reclamar una más alta representatividad que la literatura testimonial en su totalidad. Esta representatividad es resultado de la diversidad y multiplicidad de las vidas individuales y los acontecimientos sociales narrados, no intenta construir una presunta continuidad histórica y un papel de vanguardia de los subalternos. Salvo pocas excepciones, para las que la novela sigue siendo un instrumento para involucrarse en la política y sirve a intereses extraliterarios, la relación entre literatura y revolución se ha invertido: de la literatura (al servicio) de la revolución a la revolución como (pretexto de) literatura.

Las narrativas centroamericanas, y muy en especial las que se ocupan de los acontecimientos revolucionarios, son un repositorio y laboratorio de conocimientos y experiencias de la vida y de la sobrevivencia, un medio experiencial y experimental ineludible para la convivencia. La literatura entendida en este sentido es una fuente imprescindible e inagotable en las "batallas de la memoria”.

\section{BiBLIOGRAFÍA}

Acevedo, Ramón Luis. “Castigo divino de Sergio Ramírez: el nuevo viejo arte de contar o una novela escrita desde la Revolución Sandinista”. Los senderos del volcán. Narrativa centroamericana contemporánea. Guatemala: Universidad de San Carlos de Guatemala, 1991. 155-69.

Alegría, Fernando. Nueva historia de la novela hispanoamericana. Hanover: Ediciones del Norte, 1986.

Barrios de Chamorro, Violeta. Sueños del corazón. Memorias. Madrid: Acento Editorial, 1996.

Belli, Gioconda. La mujer habitada. Managua: Vanguardia, 1988. El país bajo mi piel. Memorias de amor y guerra. Barcelona: Plaza \& Janés, 2001. Sofía de los presagios. Managua: Vanguardia, 1990. Waslala. Memorial del futuro. Managua: Anamá, 1996.

Bendaña Rodríguez, Alejandro. Una tragedia campesina: testimonios de la resistencia. Managua: Edit-Arte/Centro de Estudios Internacionales, 1991.

Beverley, John, y Marc Zimmerman. Literature and Politics in the Central American Revolutions. Austin: U of Texas P, 1990.

Blandón, Erick. Vuelo de cuervos. Managua: Editorial Vanguardia, 1997.

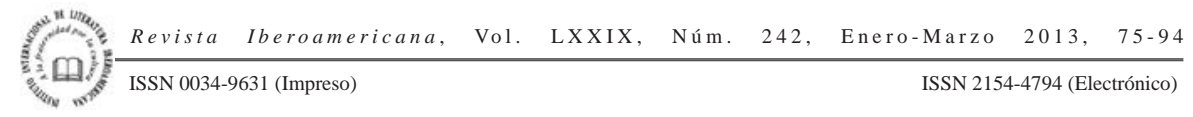


Cardenal, Ernesto. Los años de Granada: Continuación de la vida perdida. Managua: Anamá ediciones, 2004.

Las ínsulas extrañas. Memorias. Tomo II. Managua: Anamá, 2002.

La revolución perdida. Memorias. Tomo III. Managua: Anamá, 2003.

Vida perdida. Memorias. Tomo 1. Managua: Anamá, 1999.

Cardenal, Fernando. Sacerdote en la revolución. Memorias. Tomo I. Managua: Anamá, 2008.

Sacerdote en la revolución. Memorias Tomo II. Managua: Anamá ediciones, 2008.

Centeno Gómez, Julio. Atentado en el río. Managua: Centro Nicaragüense de Escritores, 2000.

Chow, Napoleón “Esperando a la gran novela sandinista”. La Prensa. 6 marzo 1998: 11A.

Cortez, Beatriz. Estética del cinismo: Pasióny desencanto en la literatura centroamericana de posguerra. Guatemala: F\&G, 2010.

"La verdad y otras ficciones: visiones críticas sobre el testimonio centroamericano". Istmo. Revista virtual de estudios literarios y culturales centroamericanos 2 (2001). $<$ http://collaborations.denison.edu/istmo/n02/articulos/testim.html>. 7 dic. 2009.

Cuadra, Pablo Antonio. “Los hijos de septiembre”. Elnicaragüense. Managua: Hispamer, 1997. 15-18.

Dobles Oropeza, Ignacio. Memorias sociales del dolor: las experiencias de las comisiones de la verdad en América Latina. Tesis doctoral. San José: Universidad de Costa Rica, 2006.

Eichendorff, Joseph Freiherr von. Aus dem Leben eines Taugenichts. München: Deutscher Taschenbuch Verlag, 1997.

Fernández-Santos, Elsa. "Sergio Ramírez narra 'la épica oculta' de la revolución sandinista. El escritor publica 'Sombras nada más', historia de la captura de un poderoso somocista”. El País. 12 marzo 2003.

Gründler, Carola. "La Novela de la Revolución Mexicana”. Apropiaciones de realidad en la novela hispanoamericana de los siglos XIX y XX. Hans Otto Dill, Carola Gründler, Inke Gunia y Klaus Meyer-Minnemann, eds. Frankfurt am Main: Vervuert; Madrid: Iberoamericana, 1994. 201-13.

Hood, Edward W. "El proceso revolucionario en Nicaragua visto por tres narradoras: Rosario Aguilar, Gioconda Belli y Mónica Zalaquett”. Proceedings of the Pacific Coast Council on Latin American Studies: Latin America in the Nineties: Transcending Current Borders 16 (1996): 99-109.

Lupiac, Georgina. Debió llamarse libertad. Managua: Hispamer, 1996.

Mackenbach, Werner. “Die unbewohnte Utopie. Zwanzig Jahre danach: Das revolutionäre Nicaragua im zeitgenössischen Roman”. Frankfurter Allgemeine Zeitung. <http:// fazarchiv.faz.net/>. 19 julio 1999.

Revista Iberoamericana, Vol. LXXIX, Núm. 242, Enero-Marzo 2013,
ISSN 2154-4794 (Electrónico) 
“Der hinkende Gutmensch. Rodrigo Rey Rosas Roman 'Die verlorene Rache”. Frankfurter Allgemeine Zeitung. <http://fazarchiv.faz.net/>. 11 dic. 2000.

"Literatura light oder bewusstes Schreiben?" Entrevista a Franz Galich. Literaturnachrichten 67 (2000): 12-14.

Die unbewohnte Utopie. Dernicaraguanische Roman der achtziger und neunziger Jahre. Frankfurt am Main: Vervuert Verlag, 2004.

"Novela de posguerra. Managua Salsa City (iDevórame otra vez!), de Franz Galich”. Áncora. Suplemento Cultural de La Nación. <http://www.nacion.com/ ancora/2001/mayo/13/ancora8.html>. 13 mayo 2001.

“La utopía deshabitada. La 'década sandinista' en tres novelas nicaragüenses de los años noventa”. Nicaragua. En el ojo del huracán / Dans l'œil du cyclone. Joël Delhom y Alain Musset, eds. París: Institute des Hautes Études de l'Amérique Latine, 2000. 237-50.

"Waslala - jenseits der Utopie. Im Norden Nicaraguas ist der Krieg noch nicht zu Ende”. Kommune. Forum für Politik, Ökonomie und Kultur 9 (1997): 35-38.

"Zum Weiterleben verurteilt. Aufruf zur Versöhnung: Manlio Arguetas Roman ‘Cuzcatlán’”. Frankfurter Allgemeine Zeitung. <http://www.faz.net/aktuell/ feuilleton/buecher/rezensionen/belletristik/rezension-belletristik-zum-weiterlebenverurteilt-110172.html>. 7 feb. 2000.

Menton, Seymour. "La novela postsandinista: Un sol sobre Managua y La lotería de San Jorge”. Caribe: Revista de Cultura y Literatura 3/2 (2000): 5-22.

"Sol y sombra: la novela postsandinista". VIII ${ }^{\circ}$ Congreso Internacional de Literatura Centroamericana. Antigua, Guatemala. 1-3 mayo 2000. Presentación de congreso. Novalis. Heinrich von Ofterdingen. München: Deutscher Taschenbuch Verlag, 1997. Núñez Soto, Orlando. Sábado de Gloria. Managua: Centro de Documentación y Ediciones Latinoamericanas, 1990.

Ortega Saavedra, Humberto. La epopeya de la insurrección. Managua: Lea Grupo, 2004. Quesada, René. En el umbral de los sueños. Managua: Hispamer, 1998.

Ramírez, Sergio. Adiós muchachos. Una memoria de la revolución sandinista. México: Aguilar, 1999.

Sombras nada más. México: Alfaguara, 2002.

Rössner, Michael. Auf der Suche nach dem verlorenen Paradies. Zum mythischen Bewußtsein in der Literatur des 20. Jahrhunderts. Frankfurt am Main: Athenäum, 1988.

Sarlo, Beatriz. Tiempo pasado. Cultura de la memoria y giro subjetivo. Una discusión. México: Siglo XXI, 2006.

Tercero,Luis Alberto. “La novela nicaragüense contemporánea: 2000-2008”. Conferencia presentada en la Universidad de Costa Rica. 12 nov. 2008.

Zalaquett, Mónica. Tu fantasma, Julián. Managua: Vanguardia, 1992.

Revista Iberoamericana, Vol. LXXIX, Núm. 242,
ISnero-Marzo 2154-4794 (Electrónico) 
Zavala, Magda. La nueva novela centroamericana. Estudio de las tendencias más relevantes del género a la luz de diez novelas del período 1970-1985. Tesis doctoral. Lovaina: Université Catholique de Louvain, 1990.

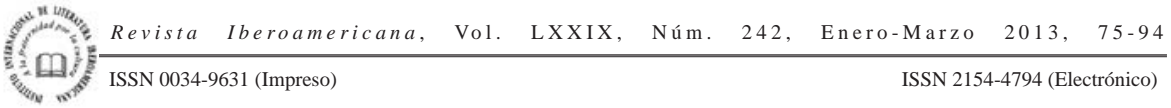

